\title{
TANGGUNG JAWAB NOTARIS YANG MEMILIKI KEWENANGAN PPAT DALAM PEMBUATAN SURAT KUASA MEMBEBANKAN HAK TANGGUNGAN
}

\author{
Stefanie Waringga Y. \\ E-mail: stefaniewaringga@gmail.com \\ Mahasiswa Fakultas Hukum Universitas Sebelas Maret \\ Albertus Sentot Sudarwanto \\ E-mail: alsentotsudarwanto@yahoo.com \\ Dosen Fakultas Hukum Universitas Sebelas Maret
}

\begin{abstract}
This article aims to review the responsibilities of a notary who has a position as an Acting Land Acting Officer (PPAT) in making a Power of Attorney to Charge Mortgage. This legal research uses empirical research methods, namely examining primary data in the field then proceed with secondary data. SKMHT must be made with a notary deed or deed of Land Deed Maker (PPAT), this is in line with what has been written and stipulated in Law Number 4 of 1996 concerning Underwriting Rights (UUHT). Making SKMHT made by a notary is guided by Article 38 of Act Number 2 of 2014 juncto Law Number 30 of 2004 concerning Notary Position, whereas if the manufacture is carried out by PPAT then follow the rules stated in the Regulation of the Head of National Land Agency Number 82012 (Perkaban 8/2012). The implementation of related regulations that have been written and stipulated is in fact there is a conflict issue, namely that there is a provision of notaries required to make SKMHT using the SKMHT format which is regulated in Perkaban Number 8 of 2012.
\end{abstract}

Keywords: Responsible; Notary; PPAT; Deed of Power of Attorney to Charge Mortgage

\begin{abstract}
Abstrak
Artikel ini bertujuan mengkaji mengenai tanggung jawab notaris yang memiliki jabatan sebagai Pejabat Pembuat Akta Tanah (PPAT) di dalam membuat Surat Kuasa Membebankan Hak Tanggungan (SKMHT). Penelitian hukum ini menggunakan metode penelitian empiris, yaitu meneliti data primer di lapangan kemudian dilanjutkan dengan data sekunder. SKMHT wajib dibuat dengan akta notaris atau akta Pejabat Pembuat Akta Tanah (PPAT), hal ini selaras dengan yang telah tertulis dan ditetapkan di dalam Undang-Undang Nomor 4 Tahun 1996 tentang Hak Tanggungan (UUHT). Pembuatan SKMHT yang dibuat oleh notaris berpedoman pada Pasal 38 Undang-Undang Nomor 2 Tahun 2014 juncto UndangUndang Nomor 30 Tahun 2004 tentang Jabatan Notaris, sedangkan apabila pembuatannya dilakukan oleh PPAT maka mengikuti aturan yang telah tertera di dalam Peraturan Kepala Badan Pertanahan Nasional Nomor 8 Tahun 2012 (Perkaban 8/2012). Implementasi regulasi terkait yang telah ditulis dan ditetapkan tersebut nyatanya justru terdapat persoalan, yakni bahwa ada ketentuan notaris diwajibkan membuat SKMHT dengan menggunakan format SKMHT yang diatur di dalam Perkaban Nomor 8 Tahun 2012.
\end{abstract}

Kata Kunci: Tanggung Jawab; Notaris; PPAT; Akta SKMHT

\section{A. Pendahuluan}

Populasi masyarakat di Indonesia semakin tahun terus bertambah berdampak pula pada kebutuhan hidup masyarakat, mulai dari kebutuhan dasar yakni: sandang, pangan, dan papan. Selain tiga hal tersebut kebutuhan lain pun turut menyusul seperti kesehatan, pendidikan, wisata, rekreasi, dll. Kebutuhan dasar atau bisa juga disebut sebagai kebutuhan primer apabila tidak terpenuhi dapat mengancam kehidupan. Sandang berarti pakaian yang dikenakan sehari-hari, pangan berarti makanan dan minuman yang dikonsumsi agar bisa bertahan hidup, dan papan berarti tempat tinggal atau hunian. Permintaan untuk hunian setiap tahun mengalami kenaikan yang 
dilatarbelakangi oleh tumbuh pesatnya masyarakat Indonesia. Pihak pengembang hunian maupun pihak bank berlomba untuk menawarkan hunian agar menarik minat masyarakat. Salah satu program yang sering ditemui di tengah masyarakat yaitu Kredit Pemilikan Rumah (KPR). Program ini menawarkan pembelian hunian dengan cara mengangsur atau biasa dikenal membayar secara kredit. Program KPR ini dalam pelaksanaannya melibatkan notaris atau PPAT.

Peran notaris atau PPAT dalam proses KPR menjadi begitu penting mengingat kedua profesi tersebut memiliki kewenangan untuk membuat akta sebagai bukti telah dilakukannya perbuatan hukum mengenai hak atas tanah. Salah satu produk yang dikeluarkan oleh notaris atau PPAT dalam proses KPR yaitu Surat Kuasa Membebankan Hak Tanggungan (SKMHT). SKMHT merupakan kuasa yang memiliki sifat khusus, tidak memuat kuasa untuk melakukan perbuatan hukum selain membebankan hak tanggungan. SKMHT telah diatur di dalam Pasal 15 Undang-Undang Nomor 4 Tahun 1996 tentang Hak Tanggungan (UUHT). Pasal 15 UUHT tertulis bahwa Surat Kuasa Membebankan Hak Tanggungan wajib dibuat dengan akta notaris atau akta PPAT. Apabila seorang notaris membuat akta SKMHT maka format yang dipakai berdasarkan Pasal 38 Undang-Undang Nomor 2 Tahun 2014 juncto Undang-Undang Nomor 30 Tahun 2004 tentang Jabatan Notaris. Berbeda dengan PPAT yang dalam pembuatan SKMHT berpedoman pada Peraturan Kepala Badan Pertanahan Nasional Nomor 8 Tahun 2012 (Perkaban 8/2012).

Implementasi dari akta SKMHT yang dibuat oleh notaris pada kenyataannya masih didapatkan bahwa pembuatan akta tersebut sering dibuat sesuai dengan format SKMHT yang diterbitkan oleh Badan Pertanahan Nasional Republik Indonesia (BPN RI), yang tentunya hal ini berpedoman pada Perkaban Nomor 8 Tahun 2012. Apabila hal ini dilakukan oleh notaris, maka yang terjadi kemudian adalah adanya pelanggaran terhadap bentuk akta notaris. Akta yang awalnya dapat disebut sebagai akta otentik maka apabila dibuat oleh seorang notaris namun tidak berpedoman pada UUJN maka akta tersebut terdegradasi menjadi akta di bawah tangan.

\section{B. Metode Penelitian}

Pada jenis penelitian ini, penulis menggunakan penelitian empiris. Penelitian empiris digunakan supaya mengetahui keadaan yang terjadi di lapangan. Pengertian penelitian empiris menurut Soerjono Soekanto adalah penelitian yang didasarkan pada metode, sistematika, dan pemikiran tertentu yang bertujuan untuk mempelajari satu atau beberapa gejala sosial tertentu dan menganalisisnya (Soerjono Soekanto, 2010:52). Pendekatan penelitian yang digunakan adalah pendekatan empiris. Pendekatan empiris adalah pendekatan yang dilakukan dengan cara mengetahui fakta-fakta yang ada atau terjadi di lapangan (masyarakat) di lokasi penelitian dengan mengumpulkan informasi-informasi tentang kejadian yang ada hubungannya dengan masalah yang akan dibahas (Lexy J. Maleong, 2005:60).

\section{Hasil Penelitian dan Pembahasan}

Profesi notaris menjadi bagian penting bagi Negara Indonesia yang menganut negara hukum sesuai dengaan Pasal 1 ayat (3) Undang-Undang Dasar Negara Republik Indonesia Tahun 1945. Notaris dalam menjalankan kewenangan dan kewajibannya dituntut untuk berperan dalam menjamin kepastian hukum, dan perlindungan hukum, serta ketertiban hukum yang mengacu pada kebenaran dan keadilan (Krisdianto R. Maradesa, 2014:1). Wewenang atau yang sering pula ditulis dengan kewenangan merupakan suatu tindakan hukum yang diatur dan diberikan kepada suatu jabatan berdasarkan peraturan perundang-undangan yang berlaku yang mengatur jabatan yang bersangkutan. Wewenang secara atribusi adalah pemberian wewenang yang baru kepada suatu jabatan berdasarkan suatu peraturan perundang-undangan atau aturan hukum. Kemudian wewenang secara delegasi merupakan pemindahan atau pengalihan wewenang yang ada berdasarkan suatu peraturan perundang-undangan atau aturan hukum (Ni Putu Selvyana Putri Pratamikha, dkk. 2016: 59). 
Notaris berdasarkan UUJN mendapat wewenang secara atribusi, karena wewenang tersebut diciptakan dan diberikan oleh UUJN sendiri (Habib Adjie, 2009:78). Mengenai kewenangan PPAT dalam peraturan yang terdapat pada Pasal 2 Peraturan Pemerintah Nomor 37 Tahun 1998 yaitu bahwa PPAT memiliki tugas pokok melaksanakan sebagian kegiatan pendaftaran tanah dengan membuat akta sebagai bukti telah dilakukannya perbuatan hukum tertentu mengenai hak atas tanah atau Hak Milik Atas Satuan Rumah Susun, yang akan dijadikan dasar bagi pendaftaran perubahan data pendaftaran tanah yang diakibatkan oleh perbuatan hukum itu. Perbuatan hukum yang dimaksud antara lain adalah: jual beli, tukar menukar, hibah, pemberian kuasa membebankan hak tanggungan, pemberian hak tanggungan, pembagian hak bersama, hibah. Pada praktiknya seorang notaris juga memiliki Asas Pelaksanaan Tugas dan Kewajiban Notaris, asas tersebut antara lain: asas kepastian hukum, asas persamaan, asas kepercayaan, asas kehati-hatian, asas profesionalitas (Hartanti Sulihandari dan Nisya Rifiani, 2013:78-88). Wesley A. Sturges dan Samuel O. Clark menyatakan bahwa definisi dari Hak Tanggungan yakni, On the other hand, the mortgage is regarded primarily as a security; the debt is the principal fact and the mortgage is collateral there to; the interest which it confers on the mortgagee is a lien on the land, and not an estate in the land; it is a thing in action, and may therefore be assigned and transferred without a conveyance of the land itself; it is personal assets, and on the death of the mortgagee it passes to his executors or administrators, and not to his heirs." (Legal Theory and Real Property Mortgages; Issue 6 Yale Law Journal Volume 37). SKMHT merupakan salah satu contoh bentuk akta otentik. SKMHT dibuat bila dalam hal pemberian hak tanggungan tidak dapat hadir di hadapan PPAT atau notaris pada pembuatan APHT. SKMHT ini juga digunakan sebagai dasar bertindak dalam pemberian Hak Tanggungan, kemudian terkait dengan keabsahan pemberian kuasa harus memuat syarat sahnya suatu perjanjian. Notaris yang memiliki jabatan sebagai PPAT perlu memperhatikan bagian kepala akta SKMHT. Hal ini penting diperhatikan sebab perlakuan yang dilakukan oleh notaris meskipun ia juga memegang peranan selaku PPAT berbeda. Letak perbedaannya yaitu SKMHT yang dibuat notaris maka sudah barang tentu bagian kepala akta juga tertulis notaris beserta penomorannya yaitu sesuai dengan nomor notariil. Begitu pula dengan PPAT, selaku PPAT tentu bagian kepala akta yakni tertulis PPAT. PPAT sebelum mengawali tugasnya sebagai membuat akta otentik juga harus melalui tahap pengangkatan. PPAT diangkat dan diberhentikan oleh Menteri Agraria dan Tata Ruang/Kepala Badan pertanahan Nasional Republik Indonesia (Urip Santoso; 2016:65). Ada beberapa hal yang perlu diketahui oleh notaris atau PPAT dalam pembuatan SKMHT yakni : tempat atau bagian formulir akta yang sudah disediakan yang tidak dipergunakan harus ditutup dengan garis penuh; setiap pencoretan dan penggantian kata, angka, dan huruf dilakukan di bagian pinggir akta dan disahkan dengan paraf para penandatangan akta; penambahan halaman dapat dilakukan apabila formulir akta tidak mencukupi dengan mencantumkan nomor akta di setiap halaman tambahan.

Pembuatan SKMHT memang diatur di dalam Pasal 15 UUHT bahwa dapat dibuat oleh notaris maupun oleh PPAT. Notaris dalam prosesnya membuat SKMHT berpedoman terhadap UUJN, namun di lain sisi untuk SKMHT mengikuti format yang telah ditetapkan di dalam Perkaban No. 8 Tahun 2012. Pembuatan ini tentunya dilihat berdasarkan ruang lingkup kerja notaris/PPAT itu sendiri. Profesi notaris memiliki tempat kedudukan di daerah kabupaten atau kota, lalu untuk wilayah jabatan meliputi seluruh wilayah provinsi di Indonesia, sedangkan wilayah kerja PPAT adalah satu wilayah provinsi yang memiliki tempat kedudukan di kabupaten atau kota di provinsi yang menjadi bagian dari daerah kerja. Berdasarkan pernyataan inilah yang kemudian membedakan bentuk akta SKMHT yang dibuat secara notariil maupun secara format Perkaban No. 8 Tahun 2012 (wawancara Bulan November 2019). Notaris yang telah membuat akta-akta otentik sesuai dengan Pasal 38 UUJN harus mampu mempertanggungjawabkan isi akta, sehingga jangan sampai mengakibatkan kerugian pada pihak notaris dan para pihak terkait di dalam akta yang telah dibuat oleh notaris. Notaris yang memiliki kewenangan membuat akta otentik tentunya tak lepas dari tanggung jawab atas kewenangannya tersebut. Tanggung jawab yang ada pada notaris tersebut adalah: 
a. Tanggung jawab perdata atas akta yang dibuatnya. Tanggung jawab ini adalah tanggung jawab terhadap kebenaran materiil akta dalam konstruksi perbuatan melawan hukum (Kunni Afifah, 2017:151). Sanksi perdata berupa penggantian biaya, ganti rugi, dan bunga merupakan akibat yang diterima notaris dari gugatan para penghadap apabila akta bersangkutan terdegradasi (M. Edwin Azhari, 2018:46). Ancaman secara perdata bagi Notaris yang tidak melaksanakan kewajibannya sesuai kode etik dan UUJN dan mengakibatkan kerugian bagi pihak yang bersangkutan, maka Notaris dapat digugat secara perdata sesuai Pasal 1365 KUHPerdata (Muhammad Tiantanik Citra Mido dkk, 2018:167).

b. Tanggung jawab pidana atas akta yang dibuatnya. Pidana dalam hal ini adalah perbuatan pidana yang dilakukan oleh seorang notaris dalam kapasitasnya sebagai pejabat umum yang berwenang membuat akta bukan dalam konteks individu sebagai warga negara pada umumnya (Kunni Afifah, 2017:151). Notaris dapat dipidana apabila dapat dibuktikan di pengadilan bahwa secara sengaja atau tidak sengaja notaris secara bersama-sama dengan para pihak penghadap yang membuat akta dengan maksud dan tujuan untuk menguntungkan pihak penghadap yang lain (M. Edwin Azhari, 2018:46).

c. Tanggung jawab administrasi atas akta yang dibuatnya. Sanksi administrasi berdasarkan Undang-Undang Nomor 2 Tahun 2014 ada 5 (lima) jenis sanksi administrasi yang diberikan apabila seorang notaris melanggar ketentuan undang-undang tersebut, yakni: peringatan, lisan, peringatan tertulis, pemberhentian sementara, pemberhentian dengan hormat, dan pemberhentiaan dengan tidak hormat. Pendapat lain oleh Sjaifurrachman dan Philipus M. Hadjon, dkk menyatakan bahwa sanksi administratif yaitu: Paksaan pemerintahan, penarikan kembali putusan yang menguntungkan, dan pengenaan denda administratif (Sjaifurrachman dalam Ary Yuniastuti, 2018:133), serta uang paksa (dwangsom) (Philipus M. Hadjon, dkk dalam Ary Yuniastuti, 2018:133).

Seorang notaris selain tunduk pada undang-undang yang mengaturnya, ia juga perlu untuk tunduk pada kode etik. Hal ini dikarenakan notaris merupakan profesi terhormat (officium nobile) sehingga ia dituntut untuk jujur, bertanggung jawab, dan mandiri. Jurnal berjudul $A$ Review on Notarial Restriction Regulation based on Law on Office of Notary Public menuliskan bahwa UUJN provides notary to forgather in a Notary Organization known as Indonesian Notary Association (INI), it is the only free and independent association of profession for Notary which aim is to enhance the quality of Notary' profession, as it is stated in article 82 of UUJN. Also, article 83 paragraph (1) of UUJN regulates that Notary organization stipulates and enforces Notary' code of ethics yang berarti bahwa UUJN mengatur mengenai wadah perkumpulan bagi notaris yaitu Ikatan Notaris Indonesia (INI). INI bersifat bebas, independen dan untuk asosiasi profesi notaris yang bertujuan meningkatkan kualitas profesi notaris (Albertus Sentot Sudarwanto, dkk, 2018:320). Nilai-nilai di dalam kode etik notaris merupakan harkat martabat seorang notaris. Apabila notaris melanggar maka menyebabkan hilangnya harkat martabat notaris (Ignatius Ridwan Widyadhama dalam M. Edwin Azhari dan Djauhari, 2018:48). Berdasarkan publikasi dari situs nationalnotary.org yang mempublikasi tulisan yang diberi judul The Notary Public Code of Professional Responsibilty menuliskan ada beberapa guiding priciples atau prinsip panduan mengenai seorang notaris yaitu :

a. The notary shall, as a government officer and public servant, serve all of the public in an honest, fair and unbiased manner.

b. The notary shall act as an impartial witness and not profit or gain from any document or transaction requiring a notarial act, apart from the fee allowed by statue.

c. The notary shall record every notarial act in a bound journal or other secure recording device and safeguard it as an important public record.

d. The notary shall respect the privacy of each signer and not divulge or use personal or proprietary information disclosed during execution of a notarial act for other than an official purpose.

e. The notary shall seek instruction on notarization, and keep current on the: laws, practices, and requirements of the notarial office (www.nationalnotary.org). 
Menurut Ketevan Tsintsadze dalam jurnal yang berjudul Mortgage As A means of Guarantte dijelaskan mengenai hak tanggungan yakni a hypothec-Mortgage is a real right on immovable property made liable for the performance of an obligation. It confers on the right to follow the property into whosoever hands it may be, to take possession of it or to take it in payment, or to sell it or cause it to be sold, and, in that case, to have a preference upon the proceeds of the sale ranking. A hypotic is merely an accessory right, and subsists only as long as the obligation whose performance it secures continues to exist (Ketevan Tsintsadze ,2015:106).

SKMHT yang dibuat oleh notaris atau PPAT merupakan suatu akta otentik, hal ini telah tercantum di dalam Pasal 15 ayat (1) UUHT, kemudian merujuk pada Pasal 1 ayat (7) UUJN yang berbunyi bahwa akta notaris adalah akta otentik yang dibuat oleh atau di hadapan notaris menurut bentuk dan tata cara yang ditetapkan di dalam Undang-Undang. Akta yang dibuat oleh hanya akan menjadi otentik apabila notaris mempunyai wewenang yang meliputi empat hal yakni: notaris berwenang sepanjang menyangkut akta yang dibuat, notaris harus berwenang sepanjang mengenai kepentingan untuk siapa akta itu dibuat, notaris harus berwenang sepanjang mengenai tempat, dimana akta itu dibuat, notaris harus berwenang sepanjang mengenai waktu pembuatan akta itu(Anny Mawartiningsih dan Maryanto, 2017:121-122)

\section{Simpulan}

Tanggung jawab notaris terhadap akta yang dibuatnya yaitu: tanggung jawab administratif, tanggung jawab perdata, tanggung jawab pidana. Tanggung jawab tersebut apabila dilanggar oleh notaris dalam membuat akta otentik, maka dikenakan sanksi yang berlaku sesuai dari sudut tanggung jawabnya. Sanksi administratif yaitu: peringatan, lisan, peringatan tertulis, pemberhentian sementara, pemberhentian dengan hormat, dan pemberhentian dengan tidak hormat. Sanksi perdata yaitu: penggantian biaya, ganti rugi, dan bunga. Sanksi pidana yaitu: pidana penjara.

\section{E. Saran}

Pemerintah dalam hal ini Kementerian Hukum dan Hak Asasi Manusia (Kemenkumham) perlu mengadakan sosialisasi dan edukasi dengan staff BPN tentang pendaftaran SKMHT yang dibuat dengan format notariil. Sosialisasi dan edukasi ini hendaknya dilakukan secara periodik agar hasil dari sosialisasi dan edukasi dapat dipraktikkan, sehingga pihak staff BPN dapat menerima akta SKMHT secara notariil.

\section{F. Daftar Pustaka}

\section{Buku:}

Habib Adjie. 2009. Hukum Notaris Indonesia. Bandung: PT Refika Aditama

Hartanti Sulihandri dan Nisya Rifiani. 2013. Prinsip-Prinsip Dasar Profesi Notaris. Jakarta: Dunia Cerdas Ignatius Ridwan Widyadhama. 1994. Hukum Profesi tentang Profesi Hukum. Semarang: Ananta

Lexy J. Moleong.2000. Metodologi Penelitian Kualitatif. Bandung : PT Remaja Rosdakarya

Philipus M. Hadjon. 2018. Perlindungan Hukum bagi Rakyat di Indonesia, Sebuah Studi tentang PrinsipPrinsip Penanganannya oleh Pengadilan dalam Lingkungan Peradilan Umum dan Pembentukan Peradilan Administrasi. Surabaya: Peradaban

Soerjono Soekanto. 2010. Pengantar Penelitian Hukum. Jakarta: UI Press

Sjaifurrachman.2011. Aspek Pertanggungjawaban Notaris dalam Pembuatan Akta. Bandung: Mandar Maju

Urip Santoso. 2016. Pejabat Pembuat Akta Tanah Perspektif Regulasi, Wewenang, dan Sifat Akta. Jakarta. Prenamedia Group 
Jurnal

Albertus Sentot Sudarwanto, dkk. 2018. "A Review on Notarial Deed Restriction Regulation Based on Law on Office of Notary Public". International Journal of Multicultural and Multireligious Understanding. Volume 5 Issue 2 April 2018

Anny Mawartiningsih dan Maryanto. 2017. "Tinjauan Yuridis Praktik Pembuatan Akta Notaris dalam Hal Penghadap Menghadap dalam Kurun Waktu dan Tempat yang Berbeda". Jurnal Akta. Volume 4 Nomor 2 Juni 2014. Semarang: Fakultas Hukum Unissula

Ketevan Tsintsadze. 2015. "Mortgage as A Means of Guarantee". European Scientific Journal Special Edition. Grigol Robakidze University, Georgia. April 2015

Krisdianto R. Maradesa. 2014. "Kewenangan Serta Tanggung Jawab Hukum Atas Pembuatan Akta Otentik oleh Notaris Berdasarkan Undang-Undang Jabatan Notaris". Lex Privatum. Volume 2 Nomor 3 Agustus-Oktober 2014. Manado: Fakultas Hukum Universitas Sam Ratulangi

Kunni Afifah. 2017. "Tanggung Jawab dan Perlindungan Hukum bagi Notaris secara Perdata terhadap Akta yang Dibuatnya". Lex Renaissance. No 1 Volume 2 Januari 2017. Universitas Islam Indonesia

Muhammad Tiantanik Citra Mido, dkk. 2018. "Tanggung Jawab Perdata Notaris terhadap Akta yang Dibacakan oleh Staf Notaris di Hadapan Penghadap". Lentera Hukum. Volume 5 Issue 1 Mei 2018. Malang: Fakultas Hukum Universitas Brawijaya

Ni Putu Selvyana Putri Pratamikha, dkk. 2016. "Bentuk Surat Kuasa Membebankan Hak Tanggungan Setelah Dikeluarkannya Peraturan Kepala Badan Pertanahan Nasional Nomor 8 Tahun 2012 tentang Ketentuan Pelaksana Peraturan Pemerintah Nomor 24 Tahun 1997 tentang Pendaftaran Tanah". Acta Comitas. Volume 1 Nomor 1. Bali: Magister Kenotariatan Universitas Udayana

Wesley A. Sturges and Samuel O. Clark. 1928 "Legal Theory and Real Property Mortgages". Issue 6 Yale Law Journal Volume 37 Issue 6 April 1928

\section{Peraturan Perundang-undangan}

Undang-Undang Dasar Neegara Republik Indonesia Tahun 1945

Undang-Undang Nomor 2 Tahun 2014 jo Undang-Undang Nomor 30 Tahun 2004 tentang Jabatan Notaris

Undang-Undang Nomor 4 Tahun 1996 tentang Hak Tanggungan

Peraturan Pemerintah Nomor 37 Tahun 1998 tentang Peraturan Pemerintah Nomor 24 Tahun 2016 juncto Peraturan Pemerintah Nomor 37 Tahun 1998 tentang Peraturan Jabatan Pejabat Pembuat Akta Tanah.

\section{Website}

www.nationalnotary.org 